\title{
Painless Swelling of the Forefoot with Multiple Sinuses and Discharging Granules: Eumycetoma a Neglected Tropical Disease
}

\author{
(1) Aniruddha Mandal, (1) Subhasmita Baisya, (1) Pramit Nandy, (1) Subhadeep Mallick, (1) Somnath Das, \\ (1) Devansi Sarawgi, (1) Madhumita Das, (1) Olympia Rudra, (1) Aishwarya Prakash \\ Institute of Post Graduate Medical Training \& Research and SSKM Hospital, Clinic of Dermatology, Kolkata, India
}

Keywords: Eumycetoma, Black grains, Discharging sinus

\section{Dear Editor,}

Mycetoma is a chronic infectious disease caused by fungus and bacteria, characterized by formation of tumor like swelling with multiple sinuses discharging grains. The infection evolves from a small subcutaneous nodule but patients usually presents late with advancing disease including destruction of soft tissue and adjacent bony structure with limb deformity. It commonly affects the male between 20 to 40 years, living in rural areas and frequently reported in farmers, shepherds and workers of low socioeconomic status. The most common site of affection is forefoot, however it can affect the other parts of the body.

A 48-year-old male, farmer by occupation, came to Dermatology Outpatient Department with six years history of painless swelling of left foot which was progressive in nature. He had history of working barefoot in the field. Cutaneous examination revealed $8 \mathrm{~cm} \times 6$ $\mathrm{cm}$ sized nontendered swelling with multiple sinuses discharging serosanguinous fluid and black granules (Figure 1). The black granules were soft in consistency and their shape and size were variable (Figure 2). Webspaces of left foot was normal. There was no regional lymphadenopathy. No other abnormalities were found in left foot. Rest of the cutaneous examinations were normal. General and systemic examination were unremarkable. Standard X-ray of his foot showed no bony involvement. Laboratory tests revealed no abnormalities in hemogram.
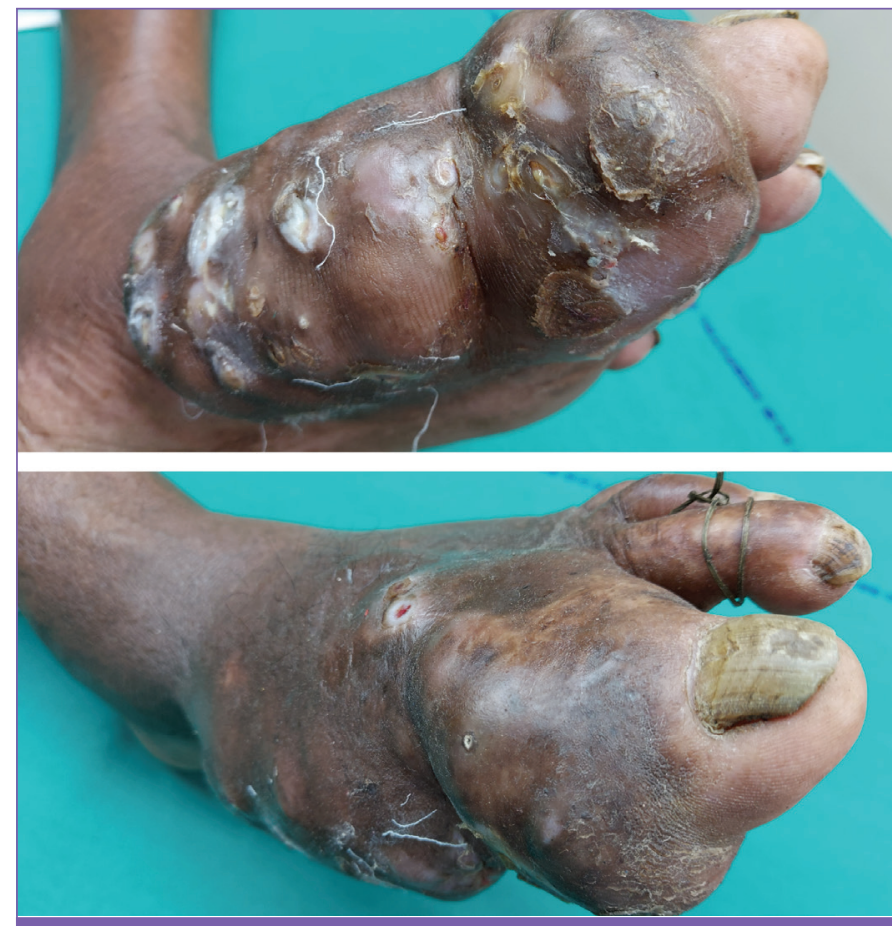

Figure 1. $8 \mathrm{~cm} \times 6 \mathrm{~cm}$ sized nontendered swelling with multiple sinuses discharging 
Information and Communications Technology Council report was negative. $\mathrm{KOH}$ mount preparation was done and black grains were found. Gram stain and Ziehl-Neelsen stain findings were insignificant. Histopathology revealed inflammatory infiltrate with sulfur graunules in a purulent area of granulation tissue. Special stain with Gomori Methenamine Silver was done and it clearly visualized the sulfur granules composed of septate hyphae, chlamydospores in deep dermis and subcutaneous tissue (Figures 3, 4) Patient was given Itraconazole 200 twice daily following histopathological report and currently patient is under treatment.

Eumycetoma is a chronic granulomatous disease caused by fungus presents with tumorous swelling, multiple discharging sinuses and black grains. Tropical eumycetoma is frequently is
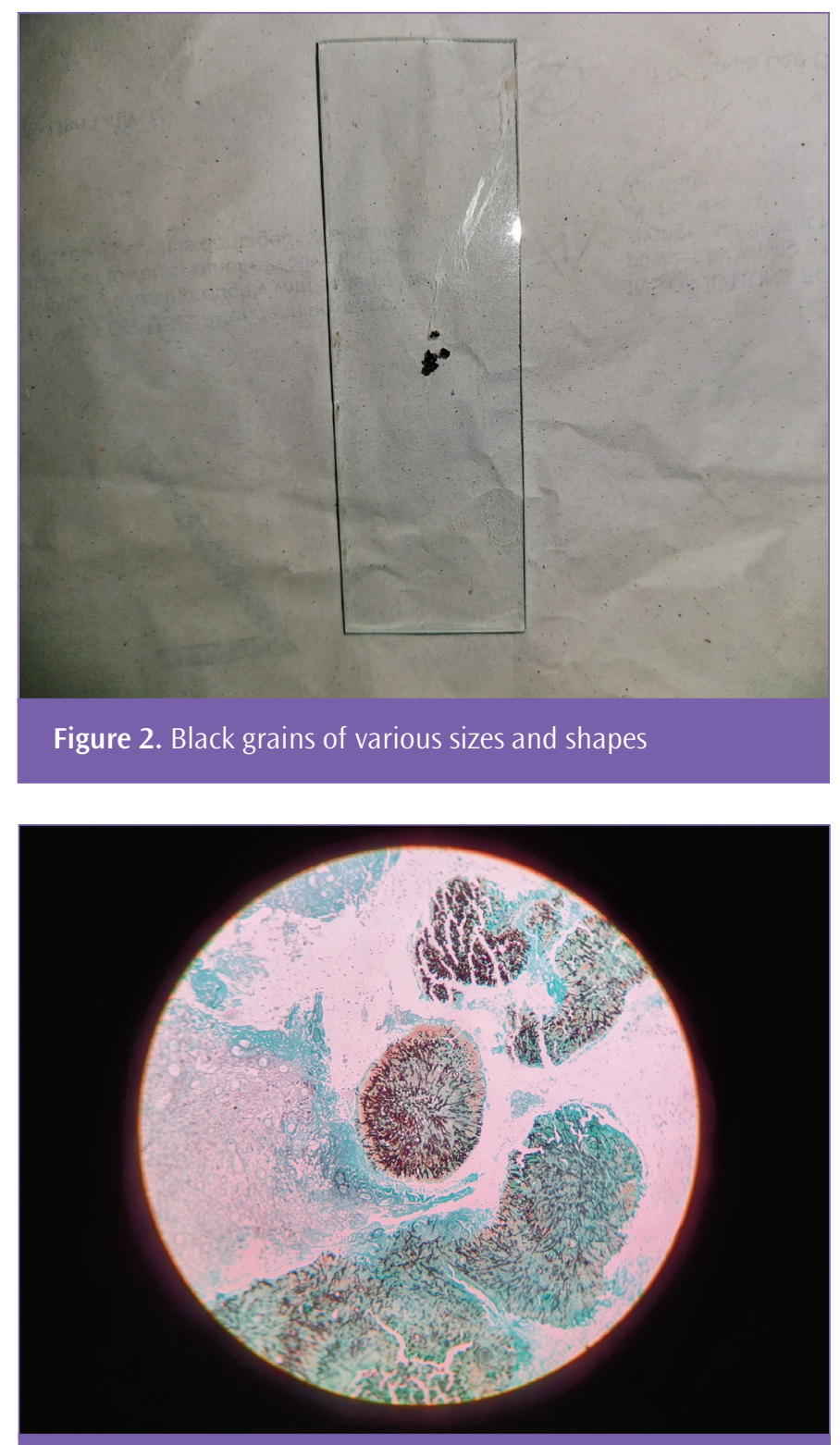

Figure 3. Gomori methenamine silver stain shows the sulfur granules at low power view (10x) caused by the fungus Madurella mycetomatis. It is responsible for most cases of black grain eumycetoma in dry arid region. In Eastern India, black grain mycetoma is caused by Madurella grisea whereas in South Madurella mycetomatis is either the dominant pathogen or the $2^{\text {nd }}$ largest group [1]. The clinical lesions, typical grains, special stain with histopathological examination are characteristic for diagnosis [2]. Most of the patients of eumycetoma were living in rural areas and involved in agricultural activities [3]. The colour of the grains are important for actinomycotic and eumycetomic differentiation. Black colour are specific to eumycetoma whereas white or yellow colour granules both in action and eumycetoma. Red grains are found in actinomadura pelletieri [4]. Radiological examination with X-ray, ultrasonography and magnetic resonance imaging are usefull to determine the extent of involvement of soft tissue and bones [5]. Diagnosis and treatment at an early stage are necessary to prevent complication [6]. For treatment of eumycetoma, high dose of oral itraconazole (400 mg once daily) is necessary [7]. Newer antifungals like voriconazole, posaconazole are indicated for resistance cases [8]. Surgercial options like local excision to amputation are indicated for resistance cases of mycetoma or not responding to conventional therapy [9]. The triad of painless swelling, macroscopically visible dark grains and patient from endemic country as well as histological demonstration of fungal hyphae and chlamydospores raised our suspicion of eumycetoma.

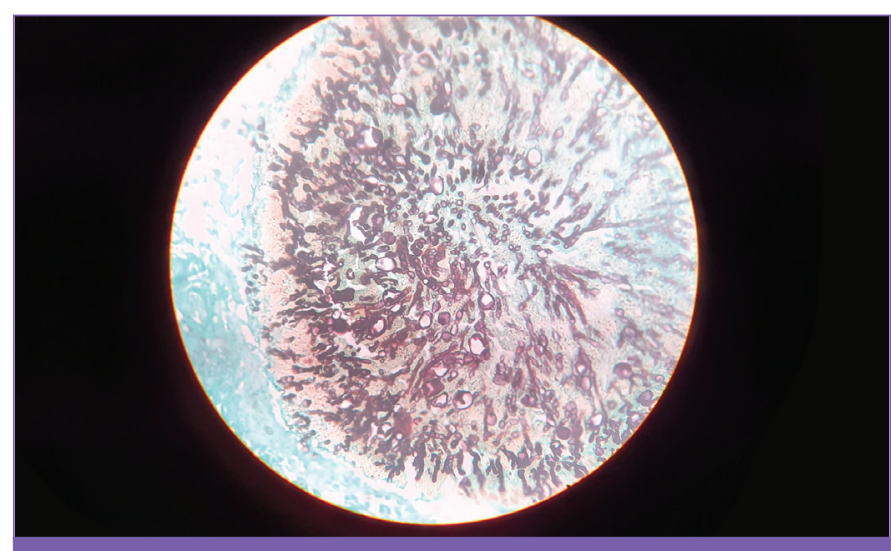

Figure 4. Gomori methenamine silver stain shows the sulfur granules composed of septate hyphae, chlamydospores at high power view (40x) 


\section{Ethics}

Informed Consent: Informed consents of all participants were obtained before the study.

Peer-review: Internally peer-reviewed.

\section{Authorship Contributions}

Surgical and Medical Practices: A.M., S.B., P.N., S.M., S.D., D.S., M.D., O.R., A.P., Concept: A.M., S.B., P.N., S.M., S.D., D.S., M.D., O.R., A.P., Design: A.M., S.B., P.N., S.M., S.D., D.S., M.D., O.R., A.P., Data Collection or Processing: A.M., S.B., P.N., S.M., S.D., D.S., M.D., O.R., A.P., Analysis or Interpretation: S.B., P.N., M.D., A.P., Literature Search: S.B., P.N., M.D., A.P., Writing: S.B., P.N

Conflict of Interest: No conflict of interest was declared by the authors.

Financial Disclosure: The authors declared that this study received no financial support.

\section{References}

1. Maiti PK, Ray A, Bandyopadhyay S. Epidemiological aspects of mycetoma from a retrospective study of 264 cases in West Bengal. Trop Med Int Health 2002;7:788-792
2. Welsh 0, Vera-Cabrera I, Salinas-Carmora MC. Mycetoma Dermatol Clin 2007;25:195-202.

3. Marc S, Meziane M, Hamada S, Hassam B, Benzekri L. Clinical and epidemiological features of Mycetoma in Morocco. Med Mal Infect 2011;41:163-164.

4. Ahmed AO, van Leeuwen W, Fahal A, van de Sande W, Verbrugh $\mathrm{H}$, van Belkum A. Mycetoma caused by Madurella mycetomatis: a neglected burden. Lancet Inf Dis 2004:4:566-574.

5. Elmaataoui A, Elmoustachi A, Aoufi S, Lyagoubi M. Eumycetoma due to Madurella mycetomatis from two cases of black grain mycetoma in Morocco. J Mycol Med 2011;21:281-284.

6. Lupi 0, Tyring SK, McGinnis MR. Tropical dermatology: fungal tropical diseases. J Am Acad Dermatol 2005:53;931-951.

7. Fahal AH, Rahman IA, El-Hassan AM, Rahman ME, Zijlstra EE. The safety and efficacy of itraconazole for the treatment of patients with eumycetoma due to Madurella mycetomatis. Trans R Soc Trop Med Hyg 2011:105;127-132.

8. Estrada R, Cha`vez-Lo`pez G, Estrada-Cha`vez G, Lo`pez-Martı́nez R, Welsh 0. Eumycetoma. Clin Dermatol 2012:30;389-396.

9. Smith EL, Kutbi S. Improvement of eumycetoma with itraconazole. J Am Acad Dermatol 1998:36;279-280. 